(1)

CrossMark

\title{
COVID-19 from the land "Down Under" in an upside-down world: an Australian perspective
}

\author{
Catherine Rang ${ }^{1}$, Allen Cheng ${ }^{2,3}$, Paul Kelly ${ }^{4}$ and Tom Kotsimbos ${ }^{1,3}$
}

Affiliations: ${ }^{1}$ Dept of Respiratory Medicine, Alfred Health, Melbourne, Australia. ${ }^{2}$ Dept of Infectious Diseases, Alfred Health, Melbourne, Australia. ${ }^{3}$ Dept of Medicine, Monash University, Alfred Campus, Melbourne, Australia. ${ }^{4}$ Australian National University Medical School, Canberra, Australia.

Correspondence: Tom Kotsimbos, Dept of Respiratory Medicine, Alfred Health, 55 Commercial Road, Melbourne, 3004 Australia. E-mail: tom.kotsimbosamonash.edu

@ERSpublications

Australia's approach to the current COVID-19 pandemic has resulted in relative containment of the disease. However, it must be remembered that any defence is only as strong as its weakest link. https:// bit.ly/2N2hHy1

Cite this article as: Rang C, Cheng A, Kelly P, et al. COVID-19 from the land "Down Under" in an upside-down world: an Australian perspective. Eur Respir J 2020; 56: 2001844 [https://doi.org/10.1183/ 13993003.01844-2020].

\footnotetext{
“Crisis (危机) = danger (危) and opportunity (机)” - Anonymous

"Knowledge is power" - Francis Bacon

"It is the long history of humankind (and animal kind, too) that those who learned to collaborate and improvise most effectively have prevailed." - Charles Darwin
}

We frame the world, which then frames all our seeing, thinking and doing [1]. This is true individually, professionally and at the level of all our institutions. It is a perpetual work in progress that occasionally undergoes a single seismic shift. This is the situation that the world is currently experiencing with severe acute respiratory syndrome coronavirus 2 (SARS-CoV-2), notwithstanding prior warnings $[2,3]$.

The origin, virological peculiarities and pathobiological nature of the SARS-CoV-2 betacoronavirus is clearly an evolving story with an uncertainty band that is very gradually narrowing [4-6]. But this narrative is only half of a much bigger picture. How the world and individual countries have responded, are responding and will respond to the unfolding pandemic will be a turning point in human history. The coronavirus disease 2019 (COVID-19) pandemic has highlighted many challenges on a multitude of levels. The largely positive Australian experience, to date, is one which can potentially provide information for shared learning for other countries globally.

Early reports from China estimated $\mathrm{R}_{0}$ to be approximately two to three, with $80 \%$ of cases being mild, $15 \%$ requiring hospitalisation and 5\% necessitating critical care [7]. These estimates have more or less held up worldwide, yet there have been dramatic variations in absolute case numbers and death rates, even between "first-world" healthcare systems [8]. This variation appears to be governed by the number of patients infected under different public health approaches ("effective" $\mathrm{R}_{0}$ ), the revelatory aspects of large case numbers, risk factor comorbidity prevalence and its effect on underlying healthcare system functionalities, agility and surge capacity $[4,9-11]$. 
Robust public health strategies are the cornerstone for managing infectious diseases, COVID-19 included. Prior to any pandemic, distinct structures and frameworks should already be well-integrated to enable the efficient and effective management of any new threat. Most of the data for "pandemic preparedness" comes from lessons learnt during previous influenza pandemics [12, 13]. As elsewhere, this holds true in Australia and, indeed, three of us were involved with several pandemic preparedness plans that flowed on from the H1N109 "swine flu" pandemic. From the beginning, it was clear that the two biggest potential mistakes were "not doing enough" such that there was not enough structural support to see a plan through, and "doing too much" which would inhibit agile decision-making and a proportional response as new information became available [14]. Additionally, restricting the frame of reference for pandemics to purely influenza clearly limits one's ability to be flexible with novel emerging infections. In a similar vein, pandemic planning should not solely be based on data gleaned from evidence-based medicine and security. A broader view, focusing on five key visions - development; economics; evidence-based medicine; human rights; and security - is a superior approach when dealing with uncertainty [15]. The World Health Organization (WHO) is instrumental in leading and coordinating pandemic response. However, WHO is subject to many structural impediments and operational deficiencies [13]. As with other pandemics, many have been critical of the WHO's COVID-19 response thus far. It must be remembered however, that the WHO has limited resources for the scope of its obligations and does not hold any legal power to enforce the adoption of its recommendations.

So far, Australia has been reasonably successful in controlling the outbreak of COVID-19. Recent new cases of less than 20 per day, with just over 100 deaths in total, have paralleled a frameshift from "flattening" the epidemic curve to "squashing" it, effectively suppressing sustained transmission chains [16].

How has this been achieved? At the very least, there was a favourable combination of high awareness from previous pandemic planning, alongside an expert informed, decisive leadership [17]. Recent leadership criticism surrounding the containment of major bushfires and their "exponential" devastation may have contributed to the early response. Initial targeted international travel bans were rapidly upscaled; quarantine, isolation and social distancing measures were progressively introduced, and effectively communicated and coordinated simultaneously. Population engagement and empowerment has been high, with over $80-90 \%$ early compliance with social distancing and personal hygiene measures. All of this has been coupled with an agile health system response to testing, patient care, resource provision and capacity building. We must acknowledge the healthy dose of geographic and seasonal good luck that Australia has been afforded as a large island, albeit very urbanised, for a population of under 26 million. Its location "Down Under", alongside quick action to delay large numbers of "seeding" cases presenting early within the pandemic, provided precious time to monitor, assess and develop cohesive plans to build health system capacity whilst the pandemic swept through other countries.

Australia's approach continues to centre around identifying and isolating cases and their contacts, improving personal hygiene, restricting travel and social distancing, with a recognition of the interdependency of all these strategies. Widespread testing has been a pivotal strategy to enable case identification. Australia's experience with early aggressive testing is in line with other countries such as South Korea and Germany, who have been able to reduce their overall number of cases and mortality rates. Consistently low positivity rates (around 1-2\% and falling) are testament to the comprehensiveness of this strategy [16]. The early social distancing and social isolation strategies have been effective, whilst thus far, not being as prohibitive in terms of social movement (New Zealand), or as intrusive (China and Taiwan) as that prosecuted by some countries. The early quarantining of returning travellers, with progressively stringent requirements, enabled effective monitoring and contact tracing. Admittedly, this is much easier to administer for island countries such as Australia and New Zealand but still requires decisive, well-coordinated leadership and high population cooperation. The UK, which has not had such stringent border controls, only recently mandating the quarantining of returning travellers, has seen far more cases and deaths. What is also important is that individual Australian states have come together in a cohesive manner; whilst there are inter-state variations in the implementation of policies, there remains a uniformity lacking in other federated countries, such as the USA. Europe has also seen many heterogeneous approaches in response to the pandemic. Whilst an alignment of the diverse healthcare systems would not have been possible, a more coordinated strategy, particularly in terms of the identification, isolation of cases and their contacts, travel restrictions and social distancing measures could have provided an enhanced European response to COVID-19, particularly as many European countries have landlocked borders.

Amongst the "unknowns" of novel emerging infections, there are some "known unknowns" from which a clear framework and a flexible approach can provide countries with a hierarchical structure for managing epidemics and pandemics [18]. As we have seen in recent months, even the best resourced healthcare systems can be overwhelmed during pandemics, and this highlights the severity such infectious disease 
threats pose. With our collective humanity in mind, there is no doubt that our best long-term pandemic management strategy is source control. Proactive strategies whereby surveillance and discovery programmes are employed and focused upon at-risk areas and populations for emerging/re-emerging infectious disease outbreaks should be implemented [19]. As always, where we draw the line between competition and co-operation will both reflect and define us as individuals, nation states and world citizens.

Looking forward, as social distancing measures are relaxed in Australia, thorough surveillance, quick detection and control of transmission chains will be essential. This must continue until herd immunity is reached and/or specific therapies or vaccines are developed. Furthermore, the use of modelling to assist with such viral emergences and their likely trajectories is a key "seeing" tool that helps inform rational decision-making with ongoing epidemic monitoring and feedback, providing an ever-improving model of the reality [20].

The current COVID-19 pandemic crisis could be likened to a labyrinth. Finding a path out requires a focus on revelatory $j i$ in the setting of all-encompassing wei such that Baconian Knowledge is transformed into Darwinian Power. And so, integrating the "Down Under" experience of COVID-19 with the rest of the world's COVID-19 pandemic trajectories so far yields a "deeper seeing" into the power of a multiplicative law involving many factors. It is therefore the weakest (and perhaps not any single strongest) link in the chain that extends from public health policy, through to institutional enactment, population engagement, collaborative communication and closed with monitoring feedback loops, that has the biggest impact on final outcomes.

Conflict of interest: C. Rang has nothing to disclose. A. Cheng is a member of Australian government advisory committees, including those involved in COVID-19; the views in this manuscript may not reflect those of these committees. P. Kelly received a salary from Australian Government Department of Health, during the conduct of the study; and is an Australian Government Department of Health senior official and a member of the medical committee advising the Government on COVID-19; the views expressed in this article are his own and may not reflect the views of that committee or the Australian Government. T. Kotsimbos has nothing to disclose.

\section{References}

1 Kotsimbos T. From the museum: the art of thinking. Eur Respir J 2014; 43: 700-701.

2 Li W, Shi Z, Yu M, et al. Bats are natural reservoirs of SARS-like coronaviruses. Science 2005; 310: 676-679.

3 Cui J, Li F, Shi ZL. Origin and evolution of pathogenic coronaviruses. Nat Rev Microbiol 2019; 17: 181-192.

4 Zhou F, Yu T, Du R, et al. Clinical course and risk factors for mortality of adult inpatients with COVID-19 in Wuhan, China: a retrospective cohort study. Lancet 2020; 395: 1054-1062.

5 Forster P, Forster L, Renfrew C, et al. Phylogenetic network analysis of SARS-CoV-2 genomes. Proc Natl Acad Sci USA 2020; 117: 9241-9243.

6 Zhou P, Yang XL, Wang XG, et al. A pneumonia outbreak associated with a new coronavirus of probable bat origin. Nature 2020; 579: 270-273.

7 Wu Z, McGoogan JM. Characteristics of and important lessons from the coronavirus disease 2019 (COVID-19) outbreak in China: summary of a report of 72314 cases from the Chinese Center for Disease Control and Prevention. JAMA 2020; 323: 1239-1242.

8 Verity R, Okell LC, Dorigatti I, et al. Estimates of the severity of coronavirus disease 2019: a model-based analysis. Lancet Infect Dis 2020; 20: 669-677.

9 Conticini E, Frediani B, Caro D. Can atmospheric pollution be considered a co-factor in extremely high level of SARS-CoV-2 lethality in Northern Italy? Environ Pollut 2020; 261: 114465.

10 Richardson S, Hirsch JS, Narasimhan M, et al. Presenting Characteristics, Comorbidities, and Outcomes Among 5700 Patients Hospitalized With COVID-19 in the New York City Area. JAMA 2020; 323: 2052-2059.

11 Intensive Care National Audit and Research Centre (ICNARC). ICNARC Case Mix Programme Database. ICNARC report on COVID-19 in critical care, 8 May 2020. London, ICNARC, 2020.

12 Holmberg M, Lundgren B. Framing post-pandemic preparedness: comparing eight European plans. Glob Public Health 2018; 13: 99-114.

13 Fineberg HV. Pandemic preparedness and response-lessons from the H1N1 influenza of 2009. N Engl J Med 2014; 370: 1335-1342.

14 Kotsimbos T, Waterer G, Jenkins C, et al. Influenza A/H1N1_09: Australia and New Zealand's Winter of Discontent. Am J Respir Crit Care Med 2010; 181: 300-306.

15 McInnes C, Lee K, Kamradt-Scott A, et al. The Transformation of Global Health Governance: Competing World Views and Crises. Aberystwyth, Aberystwyth University, 2012. www.aber.ac.uk/chair

16 Australian Governement. Department of Health. Coronavirus (COVID-19) Current Situation and Case Numbers 2020. www.health.gov.au/news/health-alerts/novel-coronavirus-2019-ncov-health-alert/coronavirus-covid-19-currentsituation-and-case-numbers Date last updated: 7 June 2020.

17 McVernon J, Sorrell TC, Firman J, et al. Is Australia prepared for the next pandemic? Med J Aust 2017; 206: 284-286.

18 Pigott DM, Deshpande A, Letourneau I, et al. Local, national, and regional viral haemorrhagic fever pandemic potential in Africa: a multistage analysis. Lancet 2017; 390: 2662-2672.

19 Lipkin WI, Anthony SJ. Virus hunting. Virology 2015; 479-480: 194-199.

20 Shearer FM, Moss R, McVernon J, et al. Infectious disease pandemic planning and response: Incorporating decision analysis. PLoS Med 2020; 17: e1003018. 